\title{
GOOGLE DRIVE: POTENCIALIDADES PARA O DESIGN DE MATERIAL EDUCACIONAL DIGITAL (MED) PARA ENSINO DE LÍNGUAS
}

\section{GOOGLE DRIVE: potentialities for the design of Digital Educational Material (DEM) for language teaching}

\author{
Rosinda de Castro Guerra RAMOS \\ Universidade Federal de São Paulo (UNIFESP), São Paulo, Brasil \\ Simone Telles Martins RAMOS \\ Faculdade de Tecnologia de São Paulo (FATEC), Ipiranga, São Paulo, Brasil \\ Fernanda Katherine ASEGA \\ (In)formação Lab, São Paulo, Brasil
}

\begin{abstract}
Resumo: Este trabalho tem como objetivo apresentar uma experiência sobre como o Google Drive pode ser usado para o desenho de MED (Material Educacional Digital) para o ensino-aprendizagem de línguas, devido ao crescente uso das TDICs (Tecnologias Digitais de Informação e Comunicação) na área de educação e aos desafios que o design de materiais educacionais para o ambiente digital nos lançam. Para apresentar nossa experiência, faremos uma discussão teórica sobre os conceitos de desenvolvimento de material didático (TOMLINSON, 2003; RAMOS, 2009), de material educacional digital -MED - (BEHAR, 2009), multimodalidade (ROJO e BARBOSA, 2015), a lacuna existente em relação ao letramento digital na formação de professores (LEFFA, 2013), os níveis/tipos de interação em ambiente digital (HIRUMI, 2013) e sua relação na coconstrução de novos conhecimentos (VIGOTSKY, 1989, 1998; OLIVEIRA, 1997; BRASIL, 1998). Em seguida, descreveremos o Google Drive e as funcionalidades dos aplicativos de produtividade Google Documentos, Planilhas, Apresentações e Formulários. Finalizaremos com considerações sobre essa experiência e suas contribuições para a área de formação de professores de línguas.
\end{abstract}

Palavras-chave: TDICs, Google Drive, MED, Ensino de Línguas

Abstract: This paper aims at presenting an experience on how Google Drive can be used to design DEM (Digital Educational Material) for teaching and learning languages, due to the increasing use of DICT (Digital Information and Communication Technology) in the educational area, and the challenges that the design of teaching materials for the digital environment offers. Before reporting our experience, the theoretical bases are presented: concepts of materials development (TOMLINSON, 2003; RAMOS, 2009); MED (BEHAR, 2009); multimodality (ROJO e BARBOSA, 2015); the digital literacy gap in teacher education; the levels/types of interaction in the digital environment (HIRUMI, 2013) and its relation in the co-construction of new knowledge (VIGOTSKY, 1989, 1998; OLIVEIRA, 1997; BRASIL, 1998). Then, Google Drive is described, as well as the functionality of Google productivity applications: Documents, Spreadsheets, Presentations, and Forms. Finally, some considerations on this experience are suggested as well as its contributions to language teacher education. 
Keywords: DICT, Google Drive, DEM, Language Teaching

\section{Introdução}

O uso das TDICs (Tecnologias Digitais de Informação e Comunicação) nas interações sociais tem promovido novas possibilidades de comunicação, interação e ensino. A contemporaneidade traz consigo novas organizações discursivas, articuladas por gêneros discursivos, que se constituem pela multimodalidade, isto é, por enunciados híbridos, textos escritos e orais que se misturam com imagens estáticas (fotos) e em movimento (vídeos) e com sons (músicas) (ROJO e BARBOSA, 2015). A exemplo disso temos os comerciais de TV, os vídeos do Youtube, as mensagens de Whats App e o uso do Google Drive para compartilhar e criar novos conteúdos, entre outros.

Em vista disso, compreender os limites e possibilidades do uso das TDICs no ensino-aprendizagem de línguas torna-se uma necessidade emergente para todo e qualquer educador que foi letrado na era do impresso e que agora precisa ser letrado digitalmente, visto que se encontra diante do desafio de (re)pensar sua prática na era digital.. Moran (2007) ressalta que as tecnologias digitais desafiam não somente professores, mas também as instituições a buscar opções para o ensino tradicional, alternando momentos presenciais com atividades on-line, como uma forma de manter vínculos pessoais e afetivos entre professores e alunos, considerando essas novas formas de comunicação e interação.

Tendo como base o cenário acima apresentado, este artigo tem como objetivo compartilhar uma experiência sobre como o Google Drive pode ser usado para a elaboração de Material Educacional Digital (MED) para o ensino de línguas. Corroborando as discussões de Leffa (2013), é possível constatar que há uma lacuna existente no processo de formação de professores de línguas em relação ao uso das TDICs na educação, ou seja, em relação ao letramento digital desses profissionais, e, com base em nossa experiência acadêmico-profissional, é possível afirmar que essa lacuna dificulta a identificação da potencialidade dos recursos existentes na internet e sua possível exploração como material didático. Assim sendo, a experiência aqui relatada visa a oferecer subsídios ao professor e também à escola, para que seja oportunizada a utilização da linguagem por meio do uso das TDICs.

Em relação ao uso do Google Drive para elaboração de MED, é importante esclarecer que o mesmo não foi criado com o objetivo de servir ao ensino-aprendizagem, como por exemplo o Moodle (uma plataforma de aprendizagem a distância), mas como uma ferramenta que roda seus programas na nuvem e disponibiliza esse tipo de serviço para todo e qualquer usuário que queira utilizá-lo. Nesse sentido, ele é entendido mais como um programa parecido com Word, Excel, Power Point, entre outros. Entretanto, com base em outras experiências (AL-ZOUBE, 2009; GATTWELL, 2007; AMPLIFICA, 
2015) advogamos que o Google Drive tem potencialidade para ser usado como recurso para a elaboração de MED, mas defendemos que essa utilização dependerá da experiência dos professores em relação à elaboração de material didático em geral e sua experiência no uso das TDICs. Assim, apoiamo-nos em Ramos (2009) que menciona que a elaboração de material didático digital, além de considerar princípios teóricos de ensinoaprendizagem, de linguagem e procedimentos que guiam essa produção, deve combinar a tipologia das atividades e seus objetivos específicos às diferentes formas de interação e às características das ferramentas que serão utilizadas para esse fim.

Com o objetivo de apresentar o Google Drive como recurso potencial para a elaboração de MED em línguas, apresentamos a seguir as bases teóricas sobre material didático, os conceitos de desenvolvimento de material didático (TOMLINSON, 2003; RAMOS, 2009), de MED (BEHAR, 2009), multimodalidade (ROJO e BARBOSA, 2015), a lacuna existente em relação ao letramento digital na formação de professores (LEFFA, 2013), os níveis/tipos de interação em ambiente digital (HIRUMI, 2013) e sua relação na coconstrução de novos conhecimentos (VIGOTSKY, 1989, 1998; OLIVEIRA, 1997; BRASIL, 1998), para em seguida descrever o Google Drive, as funcionalidades escolhidas como recursos potenciais para o design de atividades educacionais com uso desse serviço virtual. Finalizamos com considerações sobre essa experiência e suas contribuições para a área de formação de professores de línguas.

\section{Material Didático (MD) e Material Educacional Digital (MED)}

O termo Material Didático (MD) é comumente usado na área de ensinoaprendizagem de línguas e pode ser compreendido como o define Tomlison (2001, p. 66), i.e., "tudo que pode ser usado por professores ou alunos para facilitar a aprendizagem de línguas". Tomlinson (2003, p.3) explica que o processo de elaboração de materiais didáticos caminha junto com as necessidades e desejos dos alunos, mas também leva em conta as necessidades e desejos do professor e de outros envolvidos (uma instituição, por exemplo), sempre com a preocupação de estar em conformidade com princípios de aprendizagem de línguas, com um conteúdo programático e mesmo com os requisitos de políticas educacionais de um determinado lugar. Entretanto, essa explanação não faz distinção entre materiais impressos e digitais. Nesse sentido, um autor que faz menção a essa diferença é Behar (2013) que nomeia materiais para a ambientação digital de material educacional digital (MED), ou seja, "todo o material voltado à aprendizagem e que utiliza um ou mais recursos digitais na sua elaboração" (BEHAR, 2013, p. 239). Essa definição, embora indique a necessidade de utilização de um ou mais recursos digitais para sua elaboração, ainda não especifica se esse material necessita desse ou de outro(s) recurso(s) digital(is) para sua utilização. 
Nosso entendimento é que essa questão ainda carece de especificações mais detalhadas no que se refere à definição do termo e, neste trabalho faremos uso do termo MED. Todavia, elucidamos e ampliamos tal conceito para que seja redefinido como todo aquele material que pode ser usado por professores ou alunos para facilitar a aprendizagem de línguas e que no seu design (i.e., elaboração, aplicação e avaliação) incorpore recurso(s) digital(is). Por conseguinte, MED é todo material didático que em seu design incorpora recursos digitais como imagens digitais, vídeos, hipertextos, animações, games, páginas da web, entre outras ferramentas, com o objetivo de promover o processo de ensino-aprendizagem por meio da interação entre os usuários/ferramentas ou interfaces/outros para a realização de uma determinada atividade.

Além disso, o design de MED não pode ser reduzido à digitalização de materiais analógicos ou à utilização do computador em sala de aula (BEHAR, 2013, p. 239), pois, conforme atestado na literatura, materiais e recursos não são suficientes para inovar as práticas pedagógicas no mundo globalizado. A elaboração de Material Didático (MD) é sempre um grande desafio para professores e profissionais da área, mas elaborar $\mathrm{o}$ Material Educacional Digital (MED) é um desafio ainda maior porque o design de materiais didáticos para ambiente digital, conforme já apontado anteriormente, além de estar apoiado em princípios teóricos sobre linguagem e o que é ensinar e aprender, precisa também combinar a tipologia das atividades às diferentes formas de interação e às características das ferramentas que serão utilizadas para esse fim (RAMOS, 2009). Somado a isso, é preciso atentar que "o ensino pelo computador traz mudanças nas relações de tempo e espaço que, por sua vez, trazem mudanças nas interações" (RAMOS, 2009, p. 97).

Tendo como base a perspectiva sociointeracionista de linguagem, a interação é um componente integrante no processo de construção de conhecimento ${ }^{1}$ que deve ser incorporado e pensado quando da elaboração de MED, uma vez que diferentes tipos de interação podem ocorrer no ensino mediado por tecnologia digital: interação aluno-aluno, professor-aluno e aluno-conteúdo (MOORE,1989), bem como interação aluno-material externo e alunos-outros (RAMOS, 2009). Dessa forma, planejar o tipo de interação pode ser uma das tarefas mais complexas para professores de línguas, pois esses precisarão também, neste caso, aliar os objetivos de ensino-aprendizagem à escolha de ferramentas digitais que possam facilitar a coconstrução de conhecimento dos envolvidos nesse processo (VYGOTSKY, 1989).

A proposta de análise de interação de Hirumi (2013) apresenta alguns detalhamentos que vêm ao encontro desta discussão, uma vez que ilustra modos mais claros de operacionalizar esse componente no design. Um deles apresenta níveis de

\footnotetext{
${ }^{1}$ É por meio da interação que os interlocutores compartilham diferentes conhecimentos e os transformam mutuamente em um novo conhecimento (BRASIL, 1998).
} 
interação específicos para ensino mediado por tecnologia digital e o outro uma divisão das interações em humanas e não humanas, trazendo em seu bojo uma subdivisão que engloba as interações mencionadas pelos autores anteriores, conforme ilustrado na figura 1, a seguir:

Figura 1: Três níveis de interações planejadas em e-learning

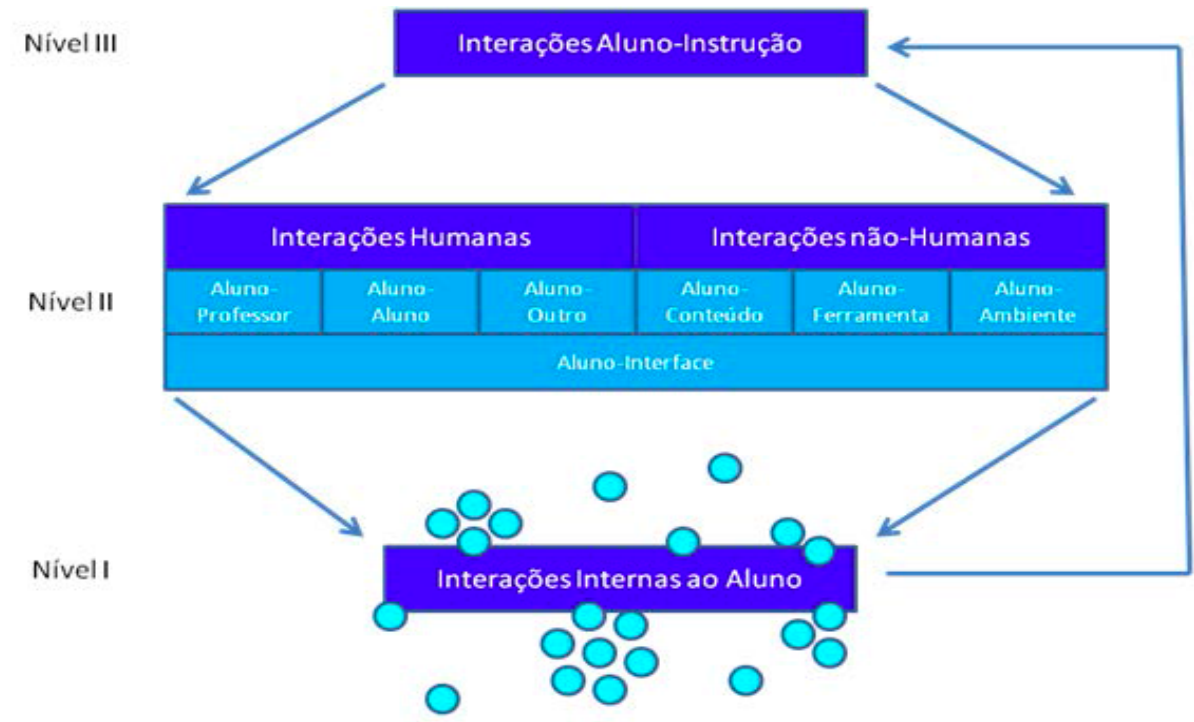

Fonte: Hirumi (2013, traduzido por MATTAR, 2013, p.10)

Conforme figura 1 acima, o nível I proposto pelo autor refere-se à interação interna do aluno, ou seja, aquela que ocorre na mente do aprendiz individualmente, i.e., aciona os processos de internalização (intrapsicológicos) para a apropriação do conhecimento (OLIVEIRA, 1997). O nível II, por sua vez, está relacionado às interações humanas (aluno, professor, outros) e não humanas (conteúdo, ferramenta, ambiente), e, nesse caso, pode-se relacioná-lo aos processos interpsicológicos oportunizados no mundo escolar pela intervenção pedagógica. Em outras palavras, por meio da interferência de outros na zona de desenvolvimento proximal $^{2}$ pode-se possibilitar a aprendizagem do indivíduo (cf. VYGOTSKY, 1998). Por fim, o nível III refere-se às interações aluno-

\footnotetext{
${ }^{2}$ Vygotsky (1998, p. 112) define a zona próxima de desenvolvimento como sendo “[...] a distância entre o nível do desenvolvimento real, que se costuma determinar através da solução independente de problemas, e o nível de desenvolvimento potencial, determinado através da solução de problemas sob a orientação de um adulto ou em colaboração com companheiros mais capazes".
} 
instrução, que definem uma estratégia de e-learning que norteia o design e o sequenciamento de interação entre o nível II que ativam as interações que ocorrem no nível I. Em vista disso, é possível dizer que o alinhamento desses três níveis influencia significativamente a elaboração de MED e de ambientes eficazes de aprendizagem online. Além disso, pode facilitar, por meio de suas diversas possibilidades de interação mediada por tecnologia digital, a coconstrução de novos conhecimentos, conforme explica Vygotsky (1989).

Isso evidencia que no design de MED não se pode focar a atenção no simples treinamento de uso das TDICs, ao invés disso, nosso foco deve recair sobre o desenvolvimento da competência digital (EUROPEAN COMMISSION, 2013, p. 2) para elaboração de MED enquanto facilitador do processo de ensino-aprendizagem de língua. Em outras palavras:

[...] a utilização das ferramentas digitais para identificar, acessar, gerenciar, integrar, avaliar, analisar e sintetizar os recursos digitais, construir novos conhecimentos, criar expressões midiáticas, e se comunicar com os outros, em contexto específico de situações reais, a fim de permitir a ação social construtiva; e refletir sobre este processo. (MARTIN; GRUDZIECKI, 2006, p.255).

O Google Drive foi o serviço virtual escolhido para ser objeto de estudo de pesquisa deste artigo que tem como propósito avaliar a potencialidade Google Drive para elaboração de MED. Vários fatores motivaram a escolha do Google Drive, a saber: gratuidade do serviço; credibilidade e aceitação dos produtos Google por usuários em geral; o extenso número de tutoriais das ferramentas Google disponíveis na Web e sua aplicação em diversos contextos; a potencialidade da ferramenta para criação de MED com textos multimodais e com diversas possibilidades de interação; o crescente número de pesquisas sobre o uso do Google no contexto educacional. (AL-ZOUBE, 2009; GATTWELL, 2007; AMPLIFICA, 2015)

De acordo com informações extraídas do site https://support.google.com, o Google Drive é um serviço de disco virtual lançado em 2004, gratuito para seus usuários que permite:

- o gerenciamento, armazenamento e sincronização de arquivos e pastas na nuvem do Google;

- o uso de aplicativos de produtividade colaborativa que oferece a criação e edição de documentos, planilhas, apresentações e formulários;

- a integração de vários aplicativos por meio da Chrome Web Store;

- a escolha de usuários no compartilhamento de arquivos por meio permissão de acesso personalizada por níveis; 
- o controle de atividade de documento por meio da criação e armazenamento de arquivos, com possibilidade de verificação de versões e modificações por seus colaboradores;

- a colaboração síncrona e assíncrona por meio do compartilhamento de documento, bate-papo, comentários;

- a incorporação de recursos de imagem, vídeos, textos, hipertextos, páginas da Web, entre outros.

Com o objetivo de identificar as potencialidades do Google Drive, selecionamos os aplicativos de produtividade Google Documentos, Planilhas, Apresentações e Formulários devido à similaridade com programas do pacote Office (i.e., Word, Excel e PowerPoint), hoje muito popularizado, e com a probabilidade de causar pouco estranhamento aos usuários, com exceção do Formulário, e sua possível utilização para design de MED. A seguir, faremos uma descrição de cada um desses aplicativos:

- Google Documentos: um processador de texto on-line que permite criar e formatar documentos de texto, ajustando margens, espaçamento, fontes e cores.

- Google Planilhas: um editor de planilhas on-line que permite criar e formatar planilhas por meio de fórmulas integradas, tabelas dinâmicas e gráficos.

- Google Apresentações: é um aplicativo de apresentações on-line que permite mostrar trabalhos de maneira visual integrando vídeos, animações e vários outros recursos.

- Google Formulários: aplicativo que permite a criação e gerenciamento de fichas de inscrição, questionários de pesquisas, entre outros. Disponibiliza diversos temas e a opção de customização de layout e composição de perguntas.

Por meio do descritivo apresentado acima, pode-se observar que o Google Drive em sua concepção não foi desenhado para finalidades educacionais, todavia apresenta potencialidades que podem ser exploradas para a elaboração de MED, já que conta com possibilidades de incorporação de recursos de imagem, vídeos, textos, hipertextos, páginas da Web, entre outros. É importante apontar também que, a despeito de sua ampla recursividade, o Google Drive é apenas um recurso tecnológico e como tal pode ser considerado como um instrumento que possibilita o design de MED. Por conseguinte, conhecer a ferramenta e compreender suas potencialidades é a primeira etapa para que se pense no design de MED. Essa etapa é seguida pelas próximas que devem combinar a tipologia das atividades às diferentes formas de interação e às características das ferramentas que serão utilizadas para esse fim (RAMOS, 2009,) com o intuito de elaborar atividades educacionais.

Passamos, então, a apresentar algumas atividades educacionais desenhadas para o ensino da Língua Inglesa que fazem uso dos aplicativos de produtividade Google, explicitando que a língua inglesa foi escolhida por nossa familiaridade e experiência profissional com essa língua, salientando, entretanto, que as atividades aqui ilustradas podem ser usadas para o ensino-aprendizagem de línguas diversas. 


\section{Atividades educacionais para o ensino de línguas utilizando o Google Drive}

Antes de passar à apresentação das atividades, é importante ressaltar que essas foram desenvolvidas para que alunos e professores possam utilizá-las em contextos educacionais nos quais se possa ter acesso à internet, tanto presencialmente como a distância, em uma tentativa de mostrar alternativas para o ensino-aprendizagem de línguas que façam uso das novas tecnologias no contexto escolar. Pensando nas características do Google Drive, elaboramos um conjunto de atividades para o ensinoaprendizagem da Língua Inglesa, respeitando as características do aplicativo e combinando-as com uma tipologia adequada a essas. No caso dos aplicativos escolhidos, as habilidades que mais se adequam a essas características são as de compreensão escrita e oral e produção escrita, pois os aplicativos escolhidos não apresentam recursos que permitem interação de voz síncrona. Entretanto, assincronamente ${ }^{3}$ é possível trabalhar o desenvolvimento da produção oral por meio de atividades que oportunizem a gravação de vídeo entre os participantes.

A primeira atividade educacional a ser exemplificada refere-se ao uso do aplicativo Google Documentos. Esse aplicativo permite a criação de textos multimodais, ou seja, textos que em sua composição recorrem a "muitas linguagens (ou modos, ou semioses)" (ROJO, 2009, p.19). Essa é uma das vantagens de se usar o recurso tecnológico de se pensar na formação do aluno do século XXI, rodeado por novas formas de comunicar-se no contexto contemporâneo, demandando, por conseguinte, diferentes habilidades de aprendizagem, novas formas de aprender e posicionar-se criticamente frente às informações e pontos de vista (LEMKE, 2010; COPE e KALANTIZIS, 2009). Esse aplicativo permite também a formatação de documentos de textos e o compartilhamento desses. Portanto, a atividade desenhada faz uso desse potencial para trabalhar o desenvolvimento das habilidades de compreensão e produção escrita para alunos que têm conhecimentos diferenciados de língua, explorando a temática “ estereótipo" por meio de leitura e escrita colaborativa. O desenho da atividade prevê a realização síncrona e/ou assíncrona da mesma, com participação de pelo menos dois alunos. A atividade é elaborada em forma de perguntas e respostas abertas, não demandando do professor conhecimentos mais específicos de tecnologia, a não ser fazer um upload de uma foto ou figura. Dos alunos, a atividade demanda: compreensão do tema por meio da interpretação da figura, seguido de escrita colaborativa sobre a mesma (cf. atividade 1); discussão do tema no bate-papo, seguida de escrita colaborativa sobre ele (cf. atividade 2). Em relação às interações, a atividade é desenhada para a ocorrência dos três níveis de interação (HIRUMI, 2013), ou seja, oferece possibilidades de interações

\footnotetext{
${ }^{3}$ No caso do uso do Google Drive, as interações assíncronas referem-se às possibilidades de interação via compartilhamento de documento, bate-papo, comentários.
} 
humanas (aluno/ professor/outros) e não humanas (conteúdo/ferramenta/ambiente) e interações aluno-instrução que podem ativar as interações que ocorrem internamente nos alunos, oportunizando a coconstrução de novos conhecimentos na língua. Salientamos também que esta atividade pode ser aplicada a alunos com diferentes níveis de conhecimento linguístico, pois, dependendo do grupo, a variação (grau de conhecimento linguístico) estará nas respostas que o professor demandará do grupo em questão.

Figura 2: MED usando o aplicativo Google Documento.

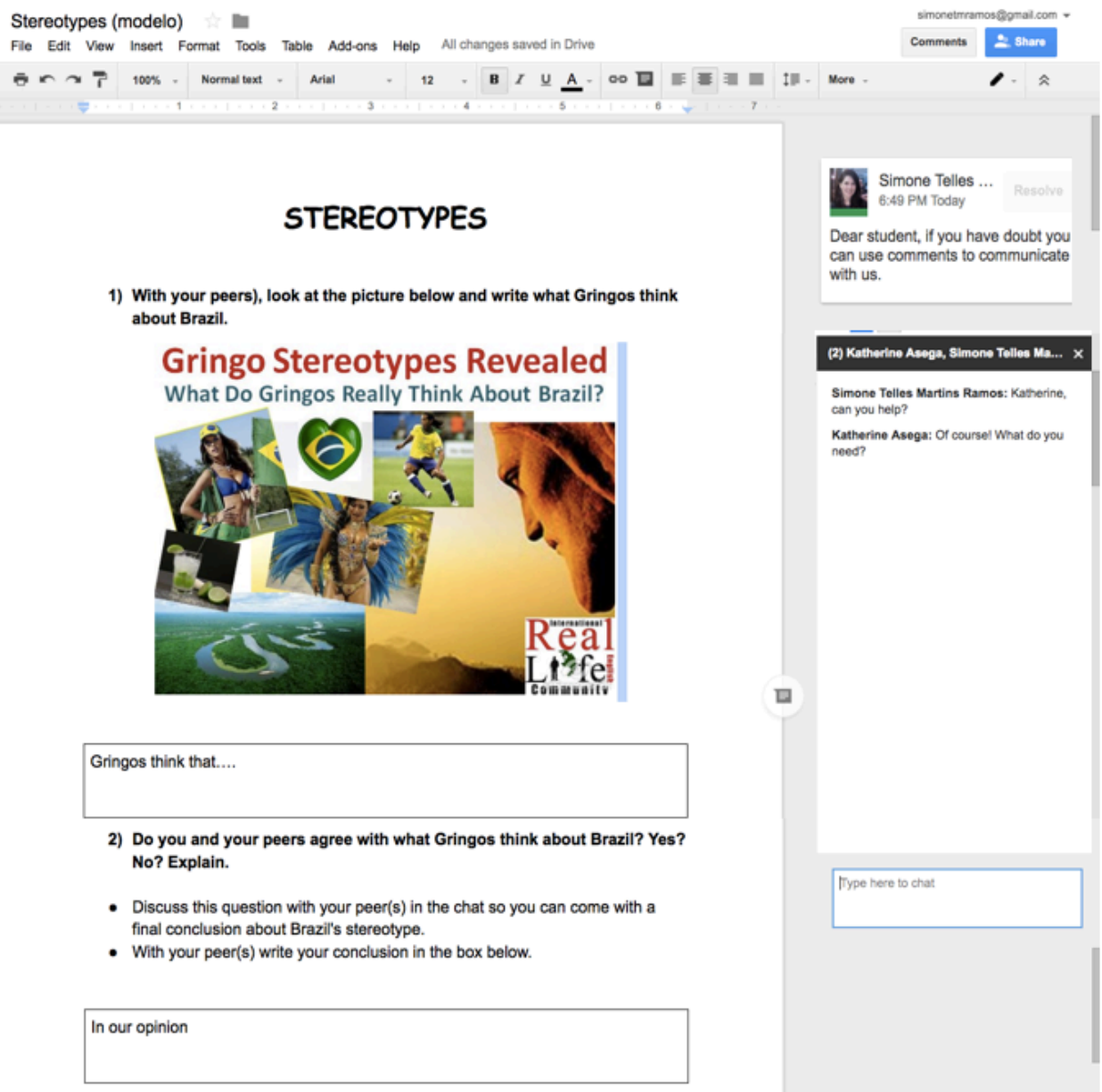

Fonte: atividade elaborada pelas autoras, disponível em $<\underline{\text { http://goo.gl/WJLHsl }>}$

A segunda atividade educacional utiliza o aplicativo Google Planilhas como uma possibilidade de design de MED. Conforme explicado anteriormente, esse aplicativo permite a criação de textos multimodais, formatação de planilhas por meio de fórmulas integradas, tabelas dinâmicas e gráficos, bem como seu compartilhamento. Essa atividade objetiva trabalhar prioritariamente a habilidade de compreensão escrita e $\mathrm{o}$ desenvolvimento de vocabulário e, neste caso, diferentemente da atividade anterior, pode exigir um grau de conhecimento linguístico um pouco maior por parte dos alunos para 
uma aplicação mais efetiva. O desenho, por sua vez, prevê a realização síncrona e/ou assíncrona da atividade, podendo ser aplicada presencialmente, de forma híbrida ou a distância, com a participação de alunos de uma mesma sala ou entre salas, com possibilidade também de gerar uma "mini" competição na escola. Esta atividade, comparada às outras deste trabalho, demandará do professor um pouco mais de conhecimento tecnológico, por conta do uso de planilha eletrônica que envolve conhecimento de fórmulas. Esta atividade faz uso de um texto multimodal para compreensão leitora, seguida de uma atividade com uso de tabela para criação de glossário, objetivando o desenvolvimento de conhecimento lexical e, finalizando com uma prática feita por meio de discussão, análise (a votação) para apropriação de vocabulário. Em relação às interações, esta atividade também é desenhada para a ocorrência dos três níveis de interação (HIRUMI, 2013), possibilitando, dessa forma, interações humanas (aluno/aluno, aluno/professor, aluno/outros) e não humanas (aluno/conteúdo, aluno/ferramenta/ambiente) e interações aluno-instrução que podem ativar as interações que ocorrem internamente nos alunos e a coconstrução do conhecimento na língua.

Figura 3: MED usando o aplicativo Google Planilhas. 


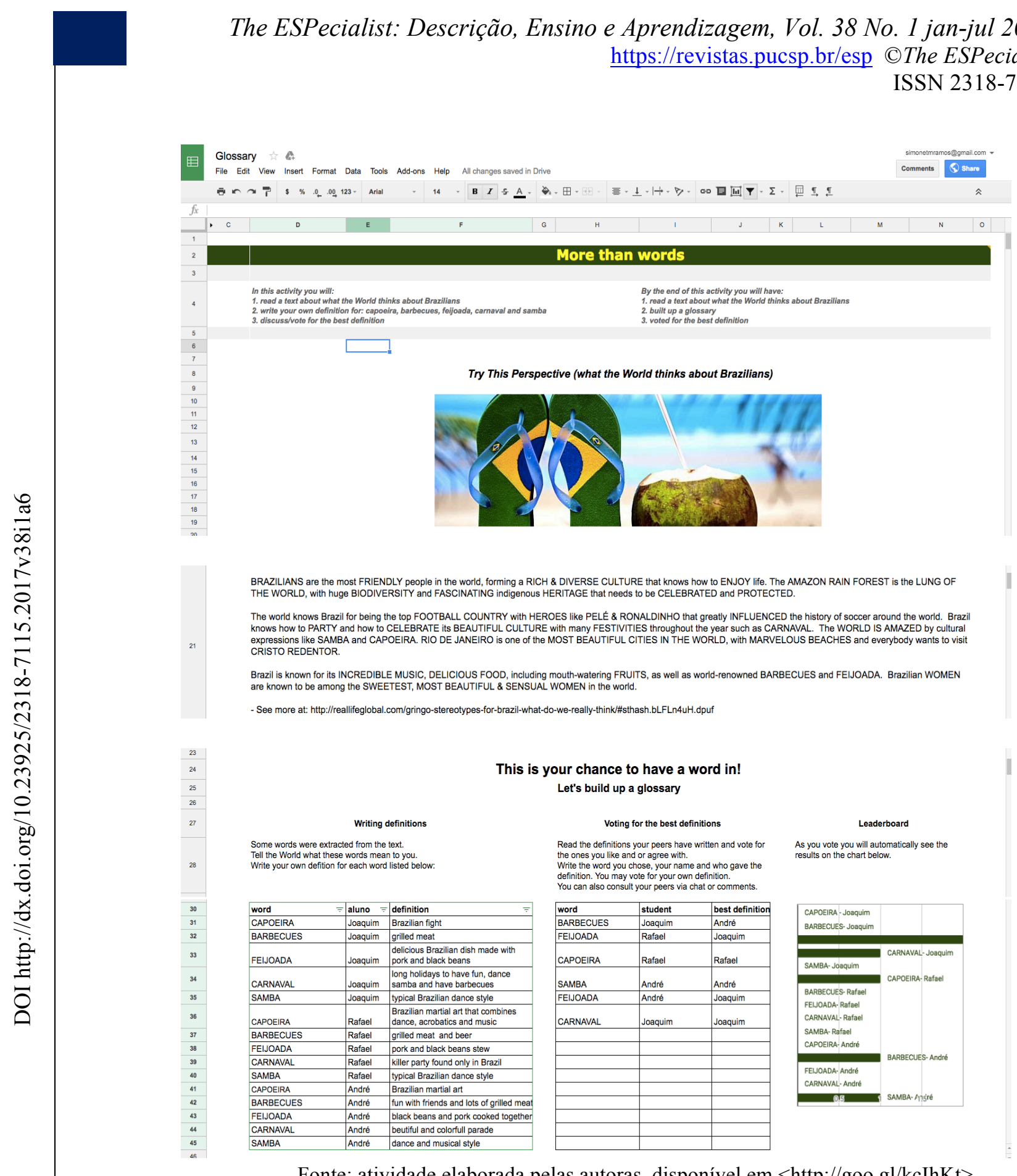

Fonte: atividade elaborada pelas autoras, disponível em $<\mathrm{http}: / /$ goo.gl/kcIhKt $>$

A próxima atividade educacional a ser exemplificada refere-se ao uso do Google Apresentações, um aplicativo de apresentações on-line que permite a criação de textos multimodais que integram vídeos, animações e vários outros recursos, bem como seu compartilhamento. Fazendo uso do potencial desse aplicativo, a atividade foi desenhada com o objetivo principal de desenvolver a habilidade de produção oral e escrita para alunos que têm pouco conhecimento da língua, explorando a temática "apresentação" por meio de um vídeo-álbum interativo. Destacamos que esta atividade, assim como já pontuado com as anteriormente descritas, pode ser utilizada com alunos cujo conhecimento linguístico é maior. O desenho da atividade prevê a realização síncrona 
e/ou assíncrona da mesma, com participação de alunos de uma mesma sala ou de mesmo nível de conhecimento linguístico. Mais uma vez a multimodalidade está presente no design da atividade, pois a produção oral dos alunos será feita por meio da gravação de um vídeo de apresentação pessoal que deverá ser inserido no slide do álbum determinado. A produção escrita será registrada ao lado do vídeo, no campo do slide chamado Personal Information. Essa, por sua vez, pode ser realizada antes, durante ou depois da gravação do vídeo, dando ao aluno liberdade de escolhas em relação às estratégias que irá utilizar para a produção oral. Em termos de conhecimentos tecnológicos, a atividade demanda do professor conhecimentos básicos de programas de apresentação. Em relação às interações, esta atividade foi desenhada priorizando a interação não-humana (alunoconteúdo/ aluno-ferramenta), todavia, devido às potencialidades do aplicativo, ela também possibilita interações humanas (aluno/ professor/outros), por meio das funcionalidades Comentários e Bate-papo que possibilitam a abertura de um canal de comunicação síncrona e assíncrona entre os participantes da atividade. Nesse caso, a ocorrência dos níveis de interação (HIRUMI, 2013) será, de uma certa forma, determinada pelo próprio participante ou pelo objetivo didático estabelecido pelo professor que irá facilitar o processo de ensino-aprendizagem da língua.

Figura 4: MED usando o aplicativo Google Apresentações.

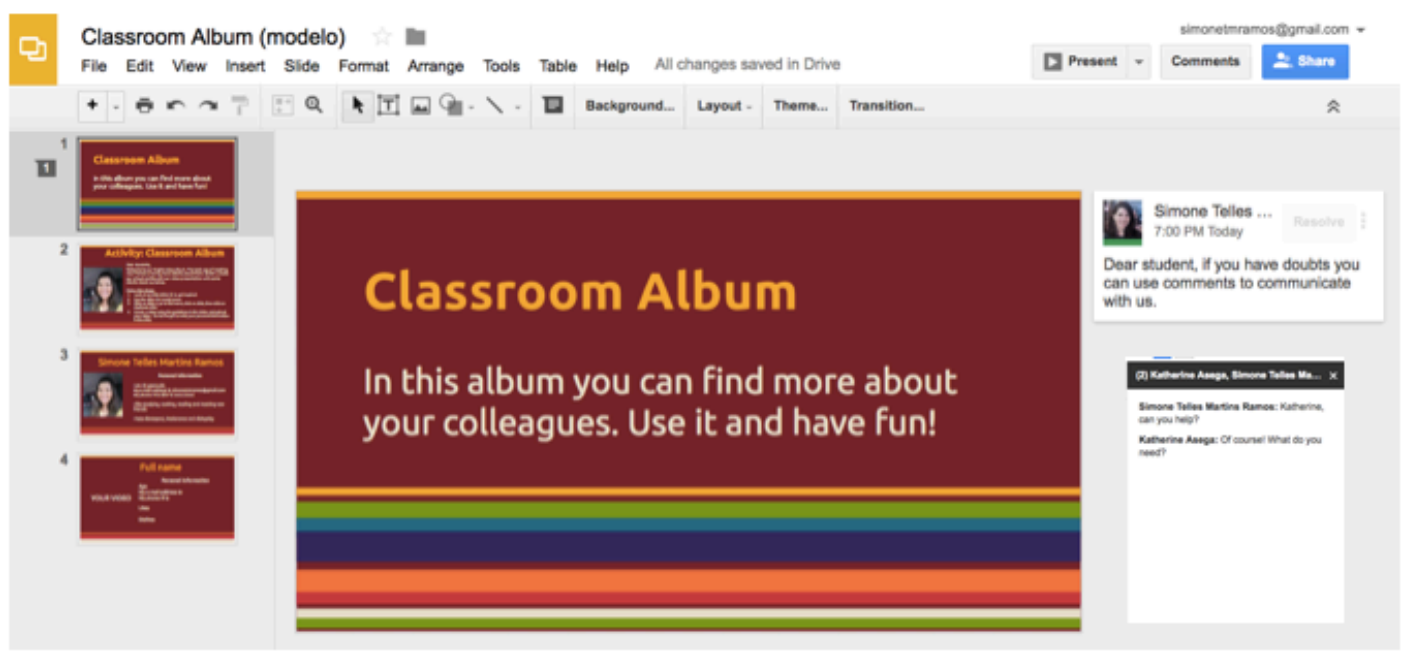

Fonte: atividade elaborada pelas autoras, disponível em $<\underline{\text { http:/goo.gl/GiiQjC }>}$

A próxima atividade educacional ilustrada refere-se ao uso do aplicativo Google Formulário. Esse aplicativo, conforme já mencionado, permite a criação e gerenciamento de fichas de inscrição, questionários, entre outros. A escolha recaiu no questionário estruturado para perguntas fechadas, com o objetivo de propiciar um trabalho individual de desenvolvimento da habilidade de compreensão oral para alunos que têm pouco conhecimento de língua, incorporando um vídeo do YouTube. A atividade é executada nessa mesma página (figura 5) e a seu término, o professor terá acesso às respostas em 
uma planilha Google (figura 6). Em relação às interações, esta atividade é de interação não-humana (aluno-conteúdo/ aluno-ferramenta). Observe-se que o design da atividade possibilita a utilização da atividade tanto para a prática individual como para a avaliação.

Figura 5: MED usando o aplicativo Google Formulário.

\section{WHAT WAS THE PROBLEM?}

Watch the video and answer the questions below.

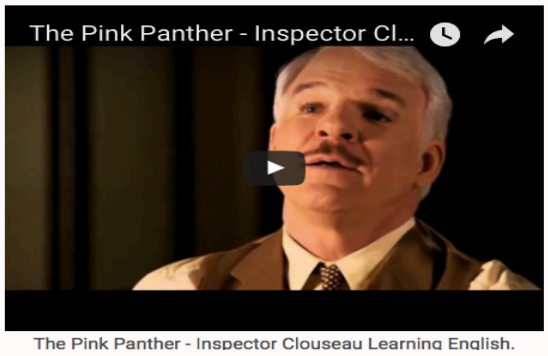

Name

1. Who was the man?

choose the best option.

2. What was the problem with him?

Choose the best option.

dd/mm/aaaa --:--

3. Why was he going to London?

Choose the best option.

To study English.

To look for a new job.

To find a criminal.

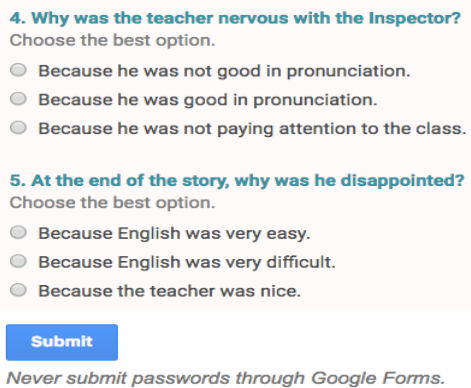

Because he was not good in pronunciation.

Because he was good in pronunciation.

Because he was not paying attention to the class.

5. At the end of the story, why was he disappointed? Choose the best option.

Because English was very easy.

Because English was very difficult.

Because the teacher was nice.

Fonte: atividade elaborada pelas autoras, disponível em $<$ https://docs.google.com/forms/d/1xlhva -qp5Bzwqn-M2q1JRifzFFHYYjImkJI1G64ek/viewform>

Figura 6: MED usando planilha eletrônica do aplicativo Google Formulário. 


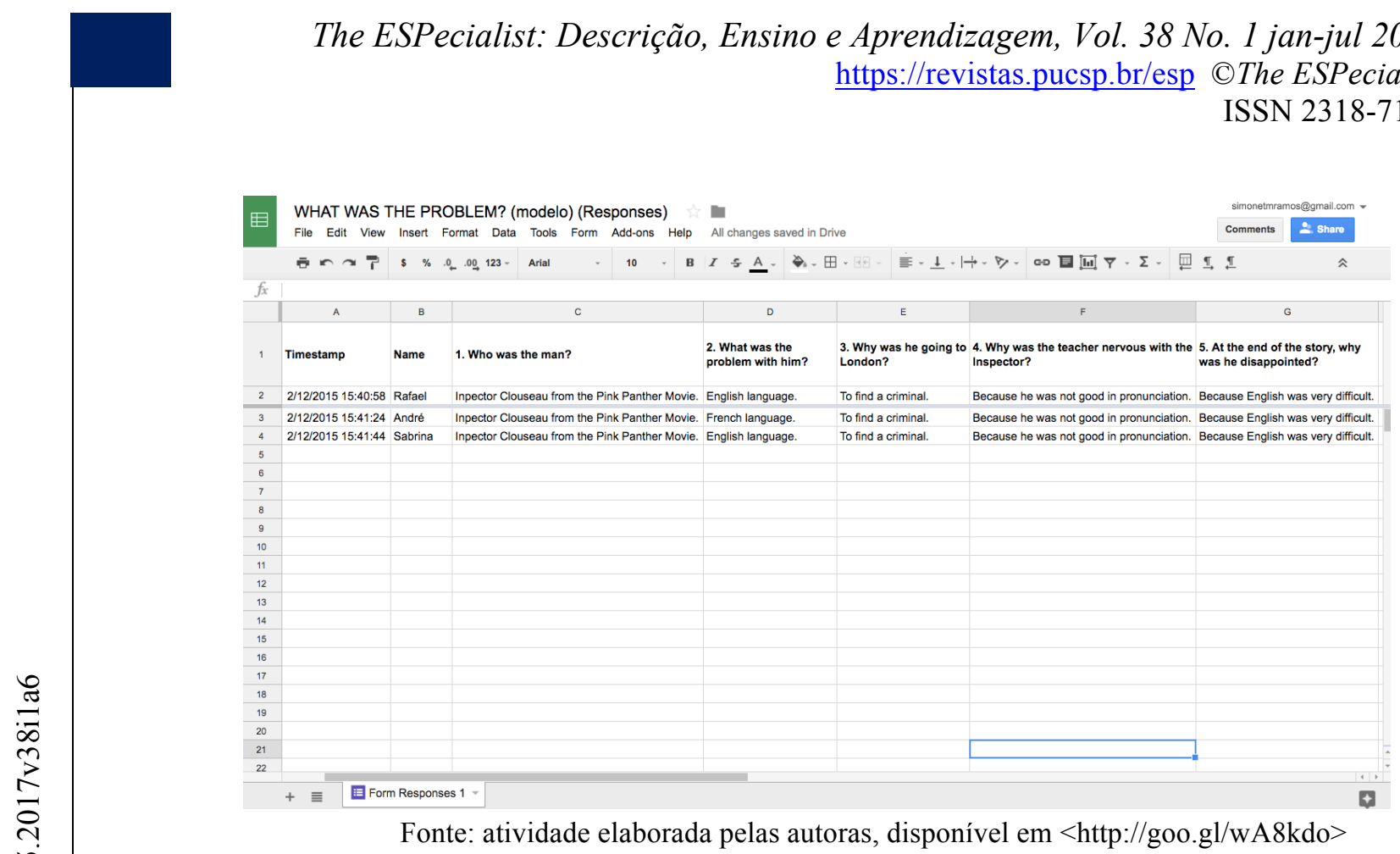

Para finalizar, gostaríamos ainda de pontuar alguns aspectos que se referem à prática do professor, entre eles, o monitoramento e o feedback de atividades. No caso dos exemplos apresentados neste trabalho, o monitoramento e o feedback de todas as atividades podem ser feitos síncrona ou assincronamente por meio das funcionalidades:

- Todas Alterações que permite ao professor visualizar a data e o horário em que os alunos acessaram as atividades, bem como o tipo de modificação feita (i.e., edição, comentário, cópia etc.).

- Comentários possibilita a abertura de um canal de comunicação do professor para o aluno e do aluno para o professor para correção, feedback, questionamentos, entre outros, uma vez que a ferramenta permite sinalizar partes do texto que requerem especial atenção.

- Bate-papo é outra ferramenta de comunicação integrada ao aplicativo que facilita a interação em tempo real.

Mediante possíveis alternativas acima, acreditamos que ao professor cabe fazer escolhas em relação ao tipo de monitoramento e feedback que dará a seus alunos, tendo sempre como base primordial a tipologia da atividade e os objetivos de ensinoaprendizagem que podem levar a coconstrução de novos conhecimentos na língua estrangeira e considerando, do mesmo modo, a potencialidade do aplicativo Google Drive que permite uma gama de possibilidades de interação que facilitarão a consecução desse processo.

\section{Considerações Finais}

Ao finalizar, é importante trazer algumas considerações sobre o recurso tecnológico escolhido e o design de MED. O Google Drive é um pacote gratuito de ferramentas de produtividade do Google que pode ser utilizado com diversos aplicativos 
de produtividade que a empresa oferece. Seu potencial pode ser expandido por meio da associação e integração de recursos Google, plataformas de ensino e dispositivos móveis como celular e tablet. Um exemplo interessante de aumento de potencialidade da ferramenta é a utilização do Google Hangout, um aplicativo destinado para interações síncronas com o uso de áudio, vídeo e chamadas em grupo, que pode contribuir, principalmente, com o desenvolvimento da produção oral. Em termos de avaliação, acompanhamento e gerenciamento do processo de ensino-aprendizagem, o Google Drive não pode ser entendido como um Ambiente Virtual da Aprendizagem (AVA), pois ele não é uma plataforma de ensino e sim um serviço que também pode ser utilizado na área educacional. Nossa sugestão foi voltada para sua aplicação na elaboração de MED para o ensino de línguas, uma vez que seus aplicativos permitem a elaboração de atividades que podem propiciar o desenvolvimento da comunicação e produção orais e escritas, conforme exemplos utilizados neste trabalho. A despeito de não ser um AVA, é importante ressaltarmos que a ampliação da potencialidade do Google Drive com a utilização de mais serviços da empresa Google pode aproximá-lo de um AVA. O fato de não termos em único ambiente a possibilidade de gerar controles administrativos ou métricos sobre o processo de ensino-aprendizagem não significa que ficamos impossibilitados de acompanhar a participação dos alunos, uma vez que temos à disposição as funcionalidades Todas Alterações, Comentários e Bate-Papo. Podemos afirmar, portanto, que o Google Drive tem grande potencial para a elaboração de MED.

O design de MED, por sua vez, é uma tarefa desafiadora, portanto envolve o letramento digital do designer e/ou professor e urge ser um componente a ser considerado nos currículos de cursos de formação de professores. É uma atividade que envolve um aprendizado sobre e de produção, avaliação e adaptação de materiais para o ensino, na qual a experiência do professor e sua relação com os novos saberes (saber ser, saber fazer e saber agir) é essencial para o sucesso dessa prática, embora muito comumente foca-se a atenção no conhecimento que o professor possui em relação à utilização das TDICs, atribuindo- se erroneamente à ferramenta a responsabilidade pelo ensino-aprendizagem de uma língua. Entretanto, conforme explica Ramos (2009), essa é uma tarefa do professor que deve combinar a tipologia das atividades às diferentes formas de interação e às características das ferramentas que serão utilizadas para esse fim, podendo gerar assim novas formas de ensinar e aprender.

\section{Referências Bibliográficas}

AL-ZOUBE, M. E-Learning on the Cloud. International Arab Journal of eTechnology, vol. 1, no. 2, June 2009. Disponível em:<

http://www.iajet.org/iajet/iajet files/vol.1/no.2/E-Learning\%20on\%20the $\% 20$ Cloud.pdf >. Acesso em: 11 jan. 2015. 
AMPLIFICA. Sala de aula transformada com as ferramentas Google. Disponível em: $<$ http://seminarioamplifica.com.br/sobre/ >. Acesso em: 20 ago. 2015.

ATTWELL G. Personal Learning Environments - the future of eLearning? eLearning Papers. Barcelona; vol 2, nº 1; Janeiro 2007. Disponível em:<

http://citeseerx.ist.psu.edu/viewdoc/download?doi=10.1.1.97.3011\&rep=rep1\&type=pd f>. Acesso em: 12 jan. 2015.

BEHAR, P.A. (orgs.). Modelos Pedagógicos em Educação a Distância. Porto Alegre: Artmed, 2009.

BRASIL. Parâmetros Curriculares Nacionais: $3^{\circ}$ e $4^{0}$ ciclos do Ensino Fundamental: Língua Portuguesa. Brasília/DF: MEC/SEF, 1998.

COPE, B.; KALANTZIS, M. Multiliteracies: new literacies, new learning, Pedagogies:

An International Journal, vol.4, 2009, p.164-195. Disponível em $<$ http://newlearningonline.com/ uploads/pedagogiesm-litsarticle.pdf $>$. Acesso em: 15. mai.2015.

EUROPEAN COMISSION. DIGCOMP: A Framework for Developing and Understanding Digital Competence in Europe. Luxembourg: Office for Official Publications of the European Communities, 2013.

GOOGLE: suporte google. Disponível em:<https://support.google.com/> Acesso em: 12 jan. 2015.

HIRUMI, A. Aplicando Estratégias Fundamentadas para Projetar e Sequenciar Interações em E-learning. Tradução João Mattar. Tecnologia Educacional. Rio de Janeiro; vol.31, no200, Janeiro-Março, 2013.p.6-41.

KRESS, G.; VAN LEEUWEN, T. Reading Images. The Grammar of Visual Design. London \& New York: Routledge, 1996/2000.

LEFFA, V. J.; MARZARI, G. Q. O letramento digital no processo de formação de professores de línguas. \# Tear: Revista de Educação Ciência e Tecnologia, Canoas, vol.2, no.2, p. 1-18, 2013.

LEMKE, J. L. Letramento metamidiático: transformando significados e midias. Trabalhos em Linguística Aplicada. Campinas, vol.49, no 2 p. 455-479, Jul./Dez. 2010. Tradução de Metamedia Literacy: Transforming Meanings and Media, 1998. Disponível em <http://www.scielo.br/pdf/tla/v49n2/09.pdf $>$. Acesso em: 20 mai.2015.

MARTIN, A. GRUDZECKI, J. DigEuLit: Concepts and Tools for Digital Literacy Development. ITALICS, vol.5, no 4, p. 249-267, 2006. Disponível em: $<$ http://www.ics.heacademy.ac.uk/italics/vol5iss4/martin-grudziecki.pdf $>$ Acesso em:11 jan. 2015.

MOORE, M. G. Three types of interaction. The American Journal of Distance Education, vol.3, no.2, p.1-6, 1989.

MORAN, J. M. Desafios na Comunicação Pessoal. $3^{\text {a }}$ ed. São Paulo: Paulinas, p.10-15, 2007. 
OLIVEIRA, M.K. Vygotsky: Aprendizado e Desenvolvimento: um processo sóciohistórico. 4a . ed. São Paulo: Scipione, 1997.

O'REILLY, T. What Is Web 2.0: Design Patterns and Business Models for the Next Generation of Software. Disponível em: $<$ http://oreillynet.com/pub/a/oreilly/tim/news/2005/09/30/what-is-web-20.html>. Acesso em: 11 jan. 2015.

RAMOS, R. C. G. Design de Material Didático on-line: reflexões. In: Soto U.; Mayrink, M.F.; Gregolin, I. V. (Org.). Linguagem, Educação e Virtualidade: experiências e reflexões. $1^{\text {a }}$ ed. São Paulo: Editora UNESP/Cultura Acadêmica, 2009. p. 93-115.

ROJO, R.;BARBOSA, J.P. Hipermodernidade, multiletramentos e gêneros discursivos. São Paulo: Parábola Editorial. 2015.

ROJO, R. Letramentos múltiplos, escola e inclusão social. São Paulo: Parábola Editorial. 2009.

TOMLINSON, B. Materials development. In: CARTER, R.; NUNAN, D. (Eds.). The Cambridge guide to teaching English for speakers of other languages. Cambridge: Cambridge University Press, 2001.p.66-71.

VYGOTSKY, L.S. Pensamento e linguagem. São Paulo, SP: Martins Fontes, 1989.

VYGOTSKY, L. S. A formação social da mente. 6. ed. São Paulo: Martins Fontes, 1998.

Rosinda de Castro Guerra Ramos is a visiting Professor at the Language Department at Federal University of São Paulo (Unifesp) and a former professor at the English Department and the Post-Graduate Programme in Applied Linguistics at Pontifical Catholic University of São Paulo. Her current publications and research interests are in the areas of English teaching, Language for Specific Purposes, teacher education, course and materials development, and Distance Education.E-mail: rramos1@uol.com.br

Simone Telles Martins Ramos holds a PhD in Applied Linguistics from the Pontifical Catholic University of São Paulo. She is a teacher of English language at Fatec-Ipiranga. Her main areas of interest are digital literacy and teacher education, digital materials development, digital learning and teaching.E-mail: simonemtramos@gmail.com

Fernanda Katherine Asega holds an MA in Applied Linguistics from Pontifical Catholic University of São Paulo. She is graduated in Design from Bandeirantes University of São Paulo (Uniban). She is currently an educational designer and a teacher of English. Her main interests are in digital course and materials design, English for Specific Purposes, digital literacy and teacher education.E-mail: katherineasega@gmail.com 